$\square$ 원 저 $\square$

$$
\begin{gathered}
\text { 편측성 훙막 삼출액환자에서 체위변화가 } \\
\text { 가스교환에 미치는 영향 }
\end{gathered}
$$

강남병원 내과

\title{
천현일·조상용·서승천·엄석준
}

증앙대학교 의 과대학 내과학교실

허 성 호

$=$ Abstract $=$

\section{The Effect of Body Positional Change on Gas Exchange in Unilateral Pleural Effusion}

Hyon II Chon, M.D., Sang Yong Cho, M.D., Seung Cheon Seo, M.D., Suk Jun Um, M.D. Department of Internal Medicine, Kang-Nam Hospital

Sung Ho Hur, M.D.

Department of Internal Medicine, College of Medicine, Chung-Ang Universizy

The effects of body position, right and left lateral decubitus, on arterial blood gases were studied in 12 patients who had unilateral pleural fluid without clinical or radiologic evidence of parenchymal lung disease. Arterial blood gases were analyzed 15 minutes after a new position. Similar studies were performed in 8 normal volunteers, the control group.

Significant difference in arterial oxygen tension $\left(\mathrm{PaO}_{2}\right)$ values between two positions were found for all patients tut not for control subject. In all 12 patients, $\mathrm{PaO}_{2}$ values were higher when the lung with the pleural fluid was upper most.

The mean $\mathrm{PaO}_{2}$ in this position was $70.9 \pm 14.2 \mathrm{mmHg}$ compared with $66.3 \pm 13.1 \mathrm{mmHg}$ in the lateral decubitus position with the pleural fluid lower most.

The mean difference in $\mathrm{PaO}_{2}$ between the two positions was $4.6 \mathrm{mmHg}$.

Because the magnitude of the differences in $\mathrm{PaO}_{2}$ values between different decubitus positions for a given patient were considerable, clinical applications of the data may be therapeutically helfful.

\section{서 론}

최근 수년동안 체위변화가 환기(換氣)기능 및 가스 교환에 미치는 영향을 이해하고자 연구가 활발히 진행 되어 이 분야에 대한 많은 진전을 보이고 있다.
이들 연구 결과에 의하던 체위(體位)는 주로 폐 내에 서 환기-관류의 균형에 변흭를 가져오므로서 가스교 환에 영향을 미친다고 한다, ${ }^{12}$.

정 상인의 호흡시에도 환기 및 관류(灌流) 가 폐의 dependent zone 에서 더 증가하게 되는테 가스교환이나 훙닥강(胸膜腔) 내압 및 폐포(肺胞)크기등도 폐의 국소 
부위에 따라 차이가 있다. 체위는 이러한 요인들의 국 소적인 차이에 영향을 줄수 있으므로 전체적인 폐기능 에 중요한 역할을 하리라고 본다.

여러 종류의 폐질환이 다양한 방법으로 국소적 환기 와 관류를 결정하는 많은 인자들에 대해 영향을 끼칠 수 있는 데 어떤 형태의 체위가 산소 포화(饱和)에 가 장 좋은가를 예견하기는 어렵다.

Zack 둥ㄱ)의 보고에 의하면 편측(片側) 폐실질에 병 변이 있을때 정상기능을 갖고 있는 폐 부위를 dependent portion 으로 할때, 병변이 있는 폐 부위를 dependent portion 으로 할때보다 산소 포화도가 높다 고 하며, 연령의 증가에 따라 closing volume 이 증가 되어 오는 $\mathrm{PaO}_{2}$ 의 감소는 좌위(座位)보다 앙와위(仰 臥位)에서 더 크다고 한다.

저자들은 정상 대조군 및 폐 실질의 질환이 없는 편 측성 홍막 삼출액 (淩出液) 환자들에서 홍막 삼출액이 체위 변화에 따라 동맥혈 가스에 미치는 영향을 관찰 하고자 본 연구를 실시하였다.

\section{대상 및 방법}

검사대상은 1985년 1월부터 6월까지 강남병원 내과 에 입원한 환자들로서 임상적으로 또는 훙부 X-선상 폐 실질에 이상소견이 없는 편측성 훙막 삼출액을 보이는 11 명의 환자를 선정 하였다.

훙막액의 용적은 훙부 X-선상 ㅎㅎㅇ막 삼출액이 늑골횡격막각 바로 상방까지 보일때 경도(輕度)로 하였고 적어도 한쪽폐의 반이상을 차지하였을때 중도(重度)로 정하였으며 경도와 중도 사이를 중등도(中等度)로 하 였다. 대상환자 모두 측와위(側臥位) X-선 촬영을 실 시하여 훙막삼출액의 유동(流動)을 확인 하였다. 대조 군은 강남병원 내과에 신체 검사를 위해 내원하여 임상 증상 및 훙부 $\mathrm{X}$-선상 정상소견을 보이는 8 명을 임의로 정 하였다.

이들 검사대상자들에 대하여 환측(患側) 및 정상측 을 dependent portion 으로 하여 각각 체위변화를 실

Table 1. Arterial Oxygen Tension in Patients with Unilateral Pleural Effusion

\begin{tabular}{|c|c|c|c|c|c|c|c|c|}
\hline \multirow[t]{2}{*}{ Patient } & \multirow[t]{2}{*}{ Sex/Age } & \multirow{2}{*}{$\begin{array}{l}\text { Fluid } \\
\text { Amount } \\
\text { and Site }\end{array}$} & \multicolumn{3}{|c|}{$\begin{array}{l}\text { Blood Gases } \\
\text { Lateral Position with } \\
\text { Sick Lung Dependent } \\
\end{array}$} & \multicolumn{2}{|c|}{$\begin{array}{l}\text { Blood Gases } \\
\text { Lateral Position with } \\
\text { Normal Lung Dependent }\end{array}$} & \multirow{2}{*}{$\begin{array}{c}\text { Increase in } \mathrm{PaO}_{2} \\
\text { When Normal } \\
\text { Lung Dependent } \\
\mathrm{mmHg}(\%)\end{array}$} \\
\hline & & & $\mathrm{PaO}_{2}$ & $(\mathrm{mmHg})$ & $\mathrm{PaCO}_{2}$ & $\mathrm{PaO}_{2} \quad(\mathrm{mmHg})$ & $\mathrm{PaCO}_{2}$ & \\
\hline 1 & $\mathrm{M} / 17$ & L-Rt. & 63 & \multirow{3}{*}{ - } & 32 & 65 & 31 & $2(3.1)$ \\
\hline 2 & $\mathrm{M} / 44$ & L-Rt. & 44 & & 33 & 47 & 31 & $3(2.1)$ \\
\hline 3 & $\mathrm{M} / 25$ & $\mathrm{~L}-\mathrm{Lt}$ & 86 & & 33 & 87 & 33 & $1(1.2)$ \\
\hline 4 & $\mathrm{M} / 72$ & L-Rt. & 40 & & 35 & 41 & 36 & $1(2.5)$ \\
\hline 5 & $\mathrm{~F} / 24$ & M-Lt. & 63 & & $3 \varepsilon$ & 67 & 33 & $4(6.3)$ \\
\hline 6 & $\mathrm{~F} / 29$ & M-Rt. & 81 & & 34 & 86 & 34 & $4(6.2)$ \\
\hline 7 & $M / 44$ & M-Rt. & 71 & & 31 & 75 & 32 & $4(5.6)$ \\
\hline 8 & $\mathrm{~F} / 52$ & M-Lt. & 69 & & 38 & 74 & 38 & $5(7.2)$ \\
\hline 9 & $\mathrm{~F} / 44$ & M-Rt. & 68 & & 41 & 73 & 40 & $5(7.4)$ \\
\hline 10 & $\mathrm{M} / 49$ & S-Rt. & 71 & & 36 & 79 & 53 & $8(11.3)$ \\
\hline 11 & $\mathrm{M} / 22$ & S-Lt. & 68 & & 27 & 75 & 29 & $7(10.3)$ \\
\hline 12 & $\mathrm{~F} / 27$ & S-Lt. & 72 & & 38 & 82 & 37 & $10(13.9)$ \\
\hline \multicolumn{2}{|c|}{ Mean \pm S.D. } & & \multicolumn{2}{|c|}{$66.3 \pm 13.1$} & $34.2 \pm 3.6$ & $70.9 \pm 14.2^{*}$ & $34.0 \pm 3$ & \\
\hline
\end{tabular}

*Significantly different from the valve obtained in the position with sick lung dependent. $(\mathrm{p}<0.01)$ M: Medium, L: Large, S: Small 
Table 2. Positional $\mathrm{PaO}_{2}$ in Normal Control Subjects

\begin{tabular}{|c|c|c|c|c|}
\hline \multirow{2}{*}{ Subject } & \multicolumn{2}{|c|}{$\mathrm{PaO}_{2}(\mathrm{mmHg})$} & \multicolumn{2}{|c|}{$\mathrm{PaCO}_{2}(\mathrm{mmHg})$} \\
\hline & RLD & LLD & RLD & LLD \\
\hline 1 & 99 & 97 & 39 & 40 \\
\hline 2 & 95 & 97 & 41 & 38 \\
\hline 3 & 86 & 88 & 38 & 39 \\
\hline 4 & 97 & 95 & 40 & 40 \\
\hline 5 & 88 & 89 & 37 & 39 \\
\hline 6 & 98 & 94 & 35 & 36 \\
\hline 7 & 107 & 105 & 37 & 36 \\
\hline 8 & 101 & 104 & 39 & 41 \\
\hline Mean \pm S.D. & $96.3 \pm 6.8$ & $96.1 \pm 6.1$ & $38.2 \pm 1.9$. & $38.6 \pm 1.8$ \\
\hline
\end{tabular}

RLD: Right lateral decubitus

LLD: Left lateral decubitus

시 하였고, 동맥혈의 표본은 각각의 체위토 15 분 경가 후 채혈하였다.

검사대상 모두 검사드중 산소 훕입이나 기계적 환기 장치를 이용하지 않고 실내 공기를 흡입 하였다. 채혈 된 포본은 즉시 어름과 함께 보관 하여 60 분이 내에 $\mathrm{PaO}_{2}, \mathrm{PaCO}_{2}, \mathrm{pH}$ 를 측정 하였고, 각각 paired $\mathrm{T}$ test 를 이용하여 통계처리 하였다.

결 과

검사결 과는 Table 1 과 같다.

훙막 삼출액이 있는 환자들에서 병변부위를 dependent portion으로 하였을해 $\mathrm{PaO}_{2}$ 의 평균치는 $66.3 \pm$ $13.1 \mathrm{mmHg}$ (mean \pm S.D.) 이었고 정상폐를 dependent portion 으로 하였을해의 $\mathrm{PaO}_{2}$ 평균치는 $70.9 \pm 14.2$ $\mathrm{mmHg}$ 였다.

두 체위간의 평균 $\mathrm{PaO}_{2}$ 차이는 $4.6 \mathrm{mmHg}$ 로 통계적 으로 매우 유의한 차이를 보였다 $(t=5.7829, p<0.01)$.

훙막 삼출액을 보이는 대상환자들의 동맥혈의 평균 $\mathrm{pH}$ 와 $\mathrm{PaCO}_{2}$ 치는 각각의 체위에 마라 정상폐를ㄹ $\mathrm{de}-$ pendent portion 으로 하였을때 $\mathrm{pH} 7.43 \pm 0.01, \mathrm{PaCO}_{2}$ $34.0 \pm 3.2 \mathrm{~mm} \mathrm{Hg}$ 였고 홍막 삼출액이 있는 폐부위를 dependent portion 으토 했을때 pH 7.44士0.01, $\mathrm{PaCO}_{2}$ $34.2 \pm 3.6 \mathrm{mmHg}$ 로 통계적으로 유의한 차이가 없었다. 경도(輕度)의 훙막 삼출액을 보이는 3 명의 환자들에 서 체위변동에 따른 $\mathrm{PaO}_{2}$ 의 차이는 $11.3 \sim 13.9 \%$ 로 중 도(重度)의 흉막 삼출액을 보인 4 명의 환자에서의 1.2
2.1\%보다 차이가 커, 훙막 삼출액의 양과 체위변화 에 따른 $\mathrm{PaO}_{2}$ 치 사이에 역비례 관계를 보였다.

대조군의 평균 $\mathrm{PaO}_{2}$ 치와 $\mathrm{PaCO}_{2}$ 치는 $\mathrm{RLD}$ (Right lateral decubitus)시 $96.3 \pm 6.8 \mathrm{mmHg}, \quad 38.2 \pm 1.9$ $\mathrm{mmHg}$ 였고 $\mathrm{LLD}$ (Left lateral decubitus)시 96.1 $6.1 \mathrm{mmHg}, 38.6 \pm 1.8 \mathrm{mmHg}$ 로 통계적으로 유의한 차 이가 없었다(Table 2).

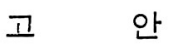

Blair 등9)이 정 상인에서 체위변화가 폐용적 과 폐포내 가스교환에 미치는 영향에 대해 연구 보고한 이래 이 에 대한 많은 연구가 진행되어왔다.

$Z \mathrm{ack}$ 능3)은 편 측 폐질환시 환측폐 (患側肺) 를 dependent portion 으로 할때 폐의 가스교환에 영향을 미친 다고 하였고, Remolina 등호도 이와 유사한 보고를 한 바 있다.

Seaton 등5)은 개훙술(開胸術)을 실시한 한자에서 수 술전에는 체위가가스교환에 영향을 끼치지 않았으나 수술후 개홍술을 실시한 폐 부위를 dependent portion 으로 했을때 가스교환에 나쁜 영향을 미치는것 을 관찰 하였다. 이러한 현상들은 중력에 의해 dependent fortion 에 혈류가 증가 하는 것으로 쉽게 설명할 수 있 다. 특히 폐렴이나 무기폐 (無氣肺) 같은경우 병변부위 가 동맥 및 정맥혈의 혼합되는 부위로 작용하는데 중 력에 의해 단락부위(短絡部位)의 관류(灌流) 가 증가되 면 단락(短絡)의 정도가 증가되어 저산소혈 증이 일어 
나게 된다. 그러나 병변부위가 상방(上方)으로 향하고 있을때는 혈액이 병변이 있는 폐부위에서 환기가 더 잘 되는 하부(下部)로 이동하기 때문에 전체적인 산소 포 화도는 증가하게 된다.

Sonnenblick 둥(6)이 보고한 바와 같이 가스교환과 체 위변동과의 관계에 영향을 미치는 또다른 인자로 훙막 삼출액에 의한 폐용적의 감소와 홍막강내 음압의 증가 딫 closing volume 의 증가에 의한 환기의 감소를 들 수 있다 ${ }^{7)}$. 그러나 이러한 변화는 또한 병변이 있는 폐 부위의 관류도 감소시키므로 어느쪽에 더 큰 영향을 미 치는지는 동맥혈 검사만으로는 알 수가 없다.

본 연구에서도 편측(片側) 폐실질에 병변이 있을배와 유사하게, 훙막 삼출액이 있는 폐 부위를 dependent portion 으로 했을배 $\mathrm{PaO}_{2}$ 가 낮아지는 것을 볼수 있었 으며 이러한 소견은 Sonnenblick 등6)의 연구성적과 유 사하였다.

훙막 삼출액이 힜는 환자들에서 각각의 측와위(側臥 位)시 $\mathrm{PaCO}_{2}$ 치는 변화가 없었으며 이는 전체적인 폐 포환기는 체위변화에 영향을 받지않음을 의미한다고 하겠다.

결 과적으로 편측 훙막 삼출액이 있을 때 가스교환에 크게 관여를 하는 인자는 환기-관류의 균형이 원활하 게 이루어지지 못한 결과로 볼 수 있는데 본 연구결과 다량의 훙막 삼출액을 보일때 각각의 체위간의 $\mathrm{PaO}_{2}$ 의 차이가 적은것은 훙막 삼출액이 다량일때 관류에 더 큰 영향을 끼쳐 병변부위의 폐가 dependent portion 을 취하고 있을때라도 병변부위의 폐에 혈류의 감소를 가져와 한기-관류불균형 정도를 감소 시키기 빼문인것 으로 여겨진다. 이러한 추정은 다량의 훙막 삼출액을 보이 는 한자의 관류-폐주사(灌流-肺走査)에서 항막 삼 출액이 있는 폐 부위에 동위원소의 섭취가 거의 안되 는 것으로 미루어 짐작할 누 있다고 한다9).

이러한 혈류감소의 기전은 정확히 알려져 있지 않으 나 계혈관계가 낮은 압력을 갖고 있으므로 다량의 훙 막 삼출액이 있을때 폐용적의 감소를 보이고 따라서 병 변부위의 폐 동맥압이 상승될 것으로 보이며 따라서 이 러한 기전에 의해 혈액을 상측(上侧) 켸부위로 이동시 키리라고 본다.

또한 국소적 저산소혈증(低酸菜血姃)이 반사기전으 로 병변부위의 혈관을 수축시켜 혈류량의 감소를 초래 할 수 있다.

경도(輕度)의 훙막 삼출액을 보이는 환자들에서 각 체위변동에 따른 $\mathrm{PaO}_{2}$ 의 차(美)가 크게 나타나는것을 볼수 있는데 이러한 소견은 아마도 증력에 의한 단락
(短絡)의 증가로 환기가 안되는 폐부위에 관류가 증가 하기 때문인 것으로 볼 수 있다.8).

본 연구결과 대조군 에서는 각각의 체위 변동에 따 라 $\mathrm{PaO}_{2}$ 및 $\mathrm{PaCO}_{2}$ 의 변화가 유의 (有意) 하지 않았음을 알수 있었고 Zack 둥노도 이와 유사한 보고를 하고 있 다.

따라서 임상에서 편축 향막삼출액이 있는 경우 삼출 액이 있는 폐부위를 상방(上方)으로 할때 가스교환에 유익하게 작용하여 산소 포화도를 증가시킬 수 있으리 라고 본다.

\section{결 론}

임상적으로 또는 방사선학적으로 폐실질에 병변이 없 는 편측 훙막 삼출액을 가진 12 명의 환자듈에서 체위 변동이 폐내(肺內) 가스교환에 미치는 영향을 관찰한 결과 홍막삼출액을 보이는 펴부위가 dependent portion 으토 있을때 평균 $\mathrm{PaO}_{2}$ 는 $66.3 \pm 13.1 \mathrm{mmHg}$ 이었 고 정상폐 부위가 dependent portion 으로 있을 때 $\mathrm{PaO}_{2}$ 는 $70.9 \pm 14.2 \mathrm{mmHg}$ 로 편측 훙막삼출액 환자에 서 정상폐 부위를 dependent portion 으로 랬을때 $\mathrm{PaO}_{2}$ 가 통계학적으토 매우 유의(有意) 하게 증가함을 알 수 있었다 $(\mathrm{p}<0.01)$.

두 체위간의 $\mathrm{PaO}_{2}$ 의 차이는 경도의 훙닥 삼출액을 보이는 환자듈에서 $11.3 \sim 13.9 \%$ 로 중도(重度)의 훙막 삼출액을 보이는 경우의 $1.2 \sim 3.1 \%$ 에 비해 크게 나타 나 훙닥 삼출액의 양과 체위 변획에 마른 $\mathrm{PaO}_{2}$ 의 차 이와는 역비례 관계를 볼 수 있었다.

\section{REFERENCES}

1) West JB, Dollery CT: Distribution of blood flow ventilation perfusion ratio in the lung, measured with radioactive $\mathrm{CO}_{2}$. J Appl physiol $15: 405,1960$

2) Bryan AC, Bentivoglio LG, Beerel F, Macleish H, Zidulka A, Bates DV: Factors affecting regional distribution of ventilation and perfusion in the lung. J Appl physiol 19:395, 1964

3) Zack MB, Pontoppidan H, Kazemi H: The effect of lateral positions on gas exchange in pulmonary disease. Am Rev Respir Dis 110: 419,1974 
4) Remoilna C, Khan AU, Santiago TV, Edelman $\mathrm{NH}$ : Positional hypoxemia in unilateral lung disease. N Engl J Med 304:523, 1981

5) Seaton D, Lapp NL, Morgan WKC: Effect of body position on gas exchange after thoracotomy. Thorax 34:518, 1979

6) Sonnenblick M, Melzer E, Rosin AJ: Body positional effect on gas exchange in unilateral pleural effusion. chest 83:784, 1983

7) Craig DB, Wahba WM, Don HE, Conture JG, Becklake MR: "Closing Volume" and its rela- tionship to gas exchange in seated and supine position. J Appl physiol 31:717, 1971

8) Katori $R$, Amorim $D$, Theye RA, Wood EH: Influence of body position on regional pulmonary arterial-vencus shunts in intact dogs. J Appl physiol 29:288, 1970

9) Blair E, Hickman JB: The effect of change in body position on lung volume and intrapulmonary gas mixing in normal subjects. $J$ Clin Invest $34: 383,1975$ 